\title{
Combined cycle power plant with indirect dry cooling tower forecasting using artificial neural network
}

\author{
Asad Dehghani Samani ${ }^{a^{*}}$
}

${ }^{a}$ Department of industrial engineering, Amirkabir University of Technology, Tehran,Iran

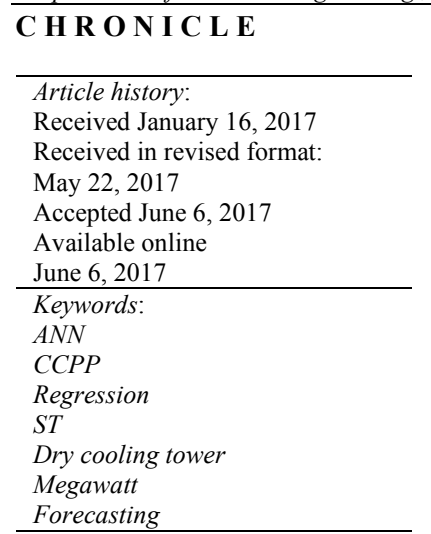
A B S T R A C T

Application of Artificial Neural Network (ANN) in modeling of combined cycle power plant (CCPP) with dry cooling tower (Heller tower) has been investigated in this paper. Prediction of power plant output (megawatt) under different working conditions was made using multilayer feed-forward ANN and training was performed with operational data using backpropagation. Two ANN network was constructed for the steam turbine (ST) and the main cooling system(MCS). Results indicate that the ANN model is effective in predicting the power plant output with good accuracy.

\section{Introduction}

The electricity generation industry all over the world has transformed into a competitive market during the last few decades. The reliable and safe operation of power plant with high performance is a constant need in order to compete with rivals. In most of the power markets, each plant has to present its power production forecast to the dispatching center which is necessary for payments. Also, performance monitoring systems are used to ensure the best output to input ratio that the power plant can yield. Thus, incorporating sophisticated monitoring and predictions systems is critical for maintaining the power plant competitiveness in the market. The per-megawatt income can be maximized with a highly accurate forecast of the power plant output. Also, reliability and maintainability of the power plant can be accomplished with comparison of the actual output and the expected value.

In order for the accurate analysis of thermodynamic systems using mathematical models, high number of parameters and assumptions are necessary which account for the actual system unpredictability

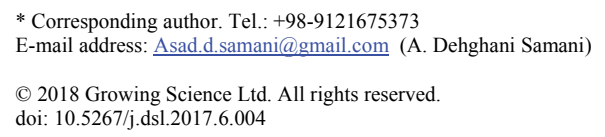


(Olausson, 2003; Tüfekci, 2014). In two studies the boiler of a thermal power plant was modeled based on conservation of energy, momentum and mass equations. The nonlinear, complicated and dynamic model of the boiler alone was derived from energy and mass relationships. The boiler was analyzed in isolation from the rest of the power plant. The results can be used for operator training and testing of boiler control systems (Bhambare et al., 2007; Liu et al., 2001a; Åström \& Bell, 2000). Similar works are also reported for the mathematical modeling of turbines. In these studies, the Steam Turbine of a power plant is analyzed in various working conditions using heat transfer principles and boundary conditions (Schobeiri \& Chaka, 2002; Bassel \& Gomes, 2002; Liu et al., 2001b; Lampart \& Yershov, 2003; Pérez et al., 2004). As can be seem, the accurate modeling of Power Plant systems based on thermodynamic laws requires many non-liner equations which are sometimes impossible to solve. This analysis takes a lot of computational time and effort although it may give a good insight about the thermodynamic process. Moreover, the accuracy of these mathematical models decreases over time because they do not consider machinery aging in the formulations. Soft computing tools like Artificial Neural Network (ANN) can be used to overcome these obstacles (Kesgin \& Heperkan,2005).

In a typical modern power plant, a large amount of parametric data is stored over long periods of time; therefore, a large data based on the operational data is always ready without any additional cost. Machine learning approaches can be used for system analysis instead of mathematical and thermodynamic models (Rich \& Knight,1991; Russell \& Norvig,1995). Different ML models can be used. ANN is a computer algorithm which uses the operational data to learn the interconnections between the input and output (Harkin, 1999). For this feature, it is highly advisable for modeling of complex systems with high degree of nonlinearity. The deviation from predicted values can be considered as an aging parameter over long periods of time. Besides, the model can be retrained to account for the aging problem. The feasibility and reliability of ANN models as a substitute for conventional simulation and analysis tool for power plant processes and components have been reported by several authors (DePold \& Goss, 1998; Embrechts et al., 2000; Bettocchi et al., 2002; Perryman \& Perot, 1994; Boccaletti et al., 2001; Ferretti \& Piroddi, 2001). The input of each Heat Recovery Steam Generator (HRSG) is from the corresponding Gas Turbine (GT) exhaust gas heat and flow. The temperature and mass flow rate are functions of the ambient conditions and the megawatt set point selected by the operator. GT power output primarily depends on the ambient temperature, pressure and relative humidity. Simulation of GT based on ANN has been done by several authors. For example, ANN technique implementation on stationary gas turbines shows that they are highly applicable in a wide range of operating conditions (Rahnama et al., 2012). In one study linear models and feed forward neural network were compared and ANN was found to yield better results (Yari \& Shoorehdeli, 2013). In other papers, ANN models were used for fault diagnosis, condition monitoring and abnormally detection (Kumar et al., 2012; Tayarani-Bathaie et al., 2014). Relatively few studies have considered the Steam Turbine (ST) in a combined cycle power plant (CCPP). In (Kesgin \& Heperkan, 2005), the total power output of a cogeneration power plant with three GT, three HRSGs and one ST were predicted. In (Pınar,2014), the output of a CCPP was analyzed using different machine learning tools. In this paper the inputs are the relative humidity, atmospheric pressure, ambient temperature and the exhaust vacuum of the ST. The exhaust steam pressure alone in a function of ambient conditions and is not a deterministic parameter.

This paper deals with the prediction analysis of the thermodynamic system including two Heat Recovery Steam Generators (HRSG) and one Steam Turbine (ST) with a dry cooling tower. One ANN model is constructed using two HRSGs and one ST. The inputs are the power output of two GTs which affect the mass flow rate of exhaust gas and the ambient temperature, which affects the exhaust flow temperature. Another ANN model is constructed to predict the exhaust steam pressure of ST which is an important parameter in ST output. The inputs are water temperatures of 6 sectors and two peak coolers, number of pumps used and the ambient temperature. Also, sensitivity analysis is performed on input data using exhaustive search technique. 
The remainder of this paper is as follows; In section 2 system description and algorithms are covered. In section 3, the study procedure is explained and in section 5 the results of the experiment are discussed and concluded.

\section{System description and methods}

\subsection{System description}

\subsubsection{Heat Recovery Steam Generator (HRSG) and Steam Turbine(ST) system}

A combined-cycle power plant uses both a gas and a steam turbine together to produce up to 50 percent more electricity from the same fuel than a traditional simple-cycle plant. The waste heat from the gas turbine is routed to the nearby steam turbine, which generates extra power. This is how a combinedcycle plant works to produce electricity and captures waste heat from the gas turbine to increase efficiency and electrical output.

1. Gas turbine burns fuel.

- The gas turbine compresses air and mixes it with fuel that is heated to a very high temperature. The hot air-fuel mixture moves through the gas turbine blades, making them spin.

- The fast-spinning turbine drives a generator that converts a portion of the spinning energy into electricity.

2. Heat recovery system captures exhaust.

- A Heat Recovery Steam Generator (HRSG) captures exhaust heat from the gas turbine that would otherwise escape through the exhaust stack.

- The HRSG creates steam from the gas turbine exhaust heat and delivers it to the steam turbine.

3. Steam turbine delivers additional electricity.

- The steam turbine sends its energy to the generator drive shaft, where it is converted into additional electricity.

Each combined cycle power plant (CCPP) module in this study is made of two gas turbines, two heat recovery steam generators and one steam turbine. The power plant from which the data for this paper was derived consists of 6 modules each including $2160 \mathrm{MW}$ Alsando V94.2 industrial gas turbine,2 Doosan two pressure HRSGs and 1 Siemens 160 MW E30 two pressure steam turbine. The GT burns compressed air with fuel injected in the combustion chamber to drive the turbine and generate electricity via the coupled generator. The GT is capable of burning natural gas and fuel oil by its dual burner design. This process generates a large flow of exhaust gas which is used in the HRSG to produce superheated steam. The HRSG consists of high pressure section and low pressure section. The steam is then used is a two section steam turbine coupled to an electricity generator.

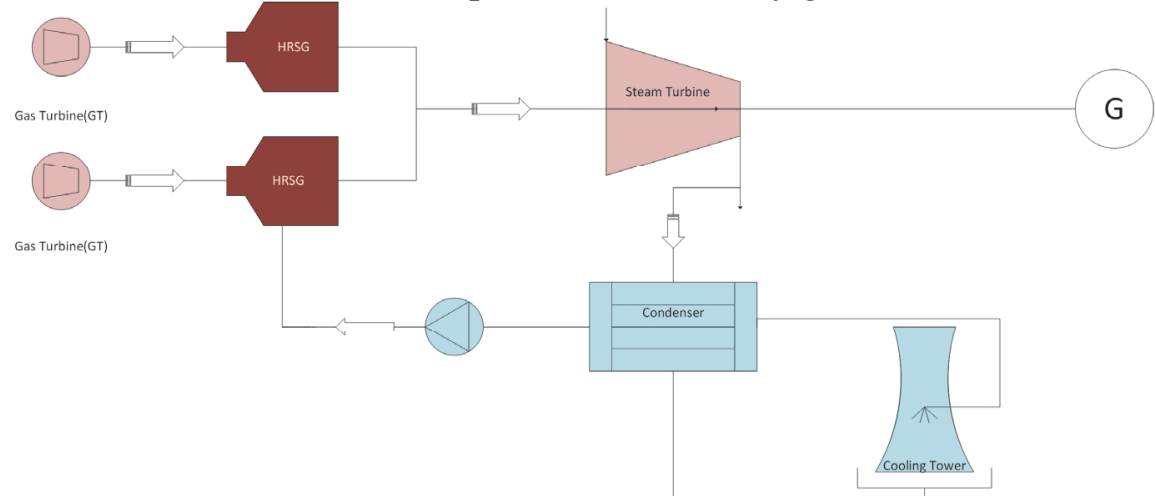

Fig. 1. Steam turbine and heat recovery steam generator overview 


\subsubsection{Main Cooling System(MCS)}

In indirect dry cooling, air is used as a secondary cooling medium. Water is still needed as primary coolant, however the cooling water flows in a closed cycle and is not in contact with the cooling air. The heat transfer between air and cooling water is achieved by convection and not by evaporation like in a wet cooling tower. The Heller system does not need any make up cooling water and does not generate plume. It means that cooling water from the cooling tower flows back to the turbine condenser to condense steam from the turbine exhaust.

If a Direct Contact jet condenser is used, the mixed cooling water and condensate are then extracted from the bottom (hot well) of the condenser by two $50 \%$ duty circulated water pumps (CWP). The major part of the water flow is returned to the tower for cooling. The cooling deltas (water to air fin tube heat exchangers) are arranged inside or outside the cooling tower and are divided into parallel sectors. These deltas dissipate the heat from the cycle. These type of systems are used for capacities of over $60 \mathrm{MW}$.

The turbine exhaust steam is condensed in the direct contact jet condenser by the re-cooled cooling water. The mixed cooling water and condensate is collected at the bottom (hot-well) of the condenser and is extracted by two circulating water pumps. The warmed up water is delivered by these two pumps to the cooling tower for cooling. The cooling deltas divided into 6 parallel sectors have the major share in cooling duty. They are assisted by cells (arranged in two sectors) of preheaters/ peak coolers parallelly connected with them. Cooling air flow is induced by the tower shell. The re-cooled water flows back to the condenser through two recovery hydro turbine connected in parallel, controlling the unwanted head by the motorized actuated guide vanes in the return main. The cooling deltas are equipped with louvers on the third (air inlet) side. The louvers are fully opened normally. If due to the low ambient air temperature a lower vacuum can be reached in the condenser, than the choking point vacuum - the cooling tower heat dissipation capacity has to be reduced by partial closing of the louvers.

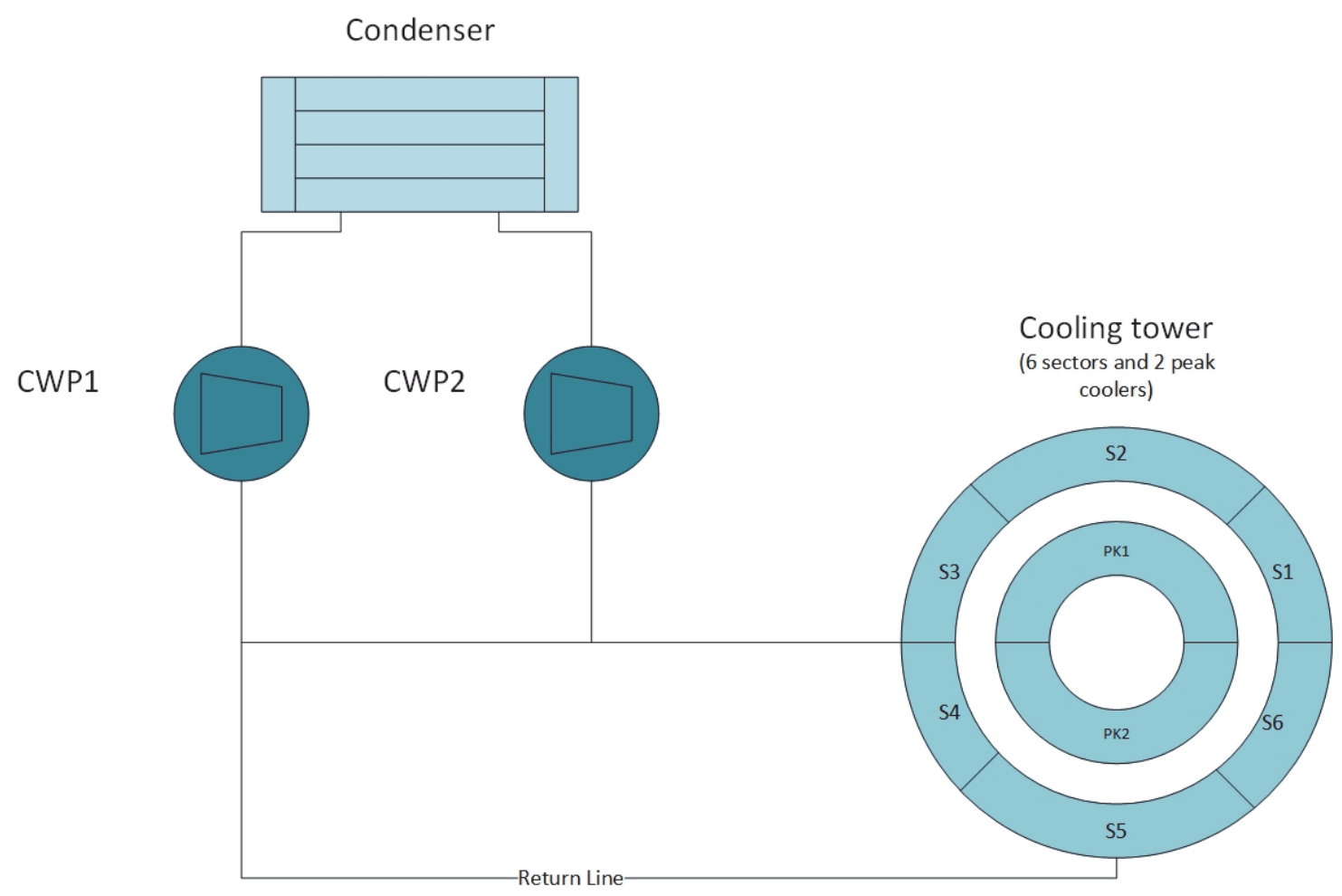

Fig. 2. Main cooling system overview 


\subsection{ANN description}

ANN is a machine learning tool which simulates the human brain. Unlike mathematical models which try to formulate the processes by mathematical and physical laws, the brain learns by creating interconnections between neurons from the life experiences. ANN mimics this iterative process by learning the relation between inputs and outputs disregarding the actual relation between them in the real world. Multi-Layer Perceptron(MLP) network consists of a number of elements called neurons with linear or nonlinear transfer functions connected with each other through weights matrix. These neurons are organized in one input layer, one or more hidden layers and one output layer as shown in Figure 3. The data is passed through the layers, multiplied by the weights matrix, summed and transferred in the processing elements (neurons) in order to produce the output. The error is calculated by comparing these outputs with actual data. The errors are then used to update the weights matrix. In each iteration (epoch), the Mean Squared Error (MSE) is calculated. As soon as the MSE is below the chosen threshold, the iterative process is terminated and the weights matrix is finalized. At this point, the network is ready to predict the output using new sets of data e.g. "unknown" data. This process is called generalization. One commercially available program for ANN development, implemented in this paper, is Matlab ANN toolbox.

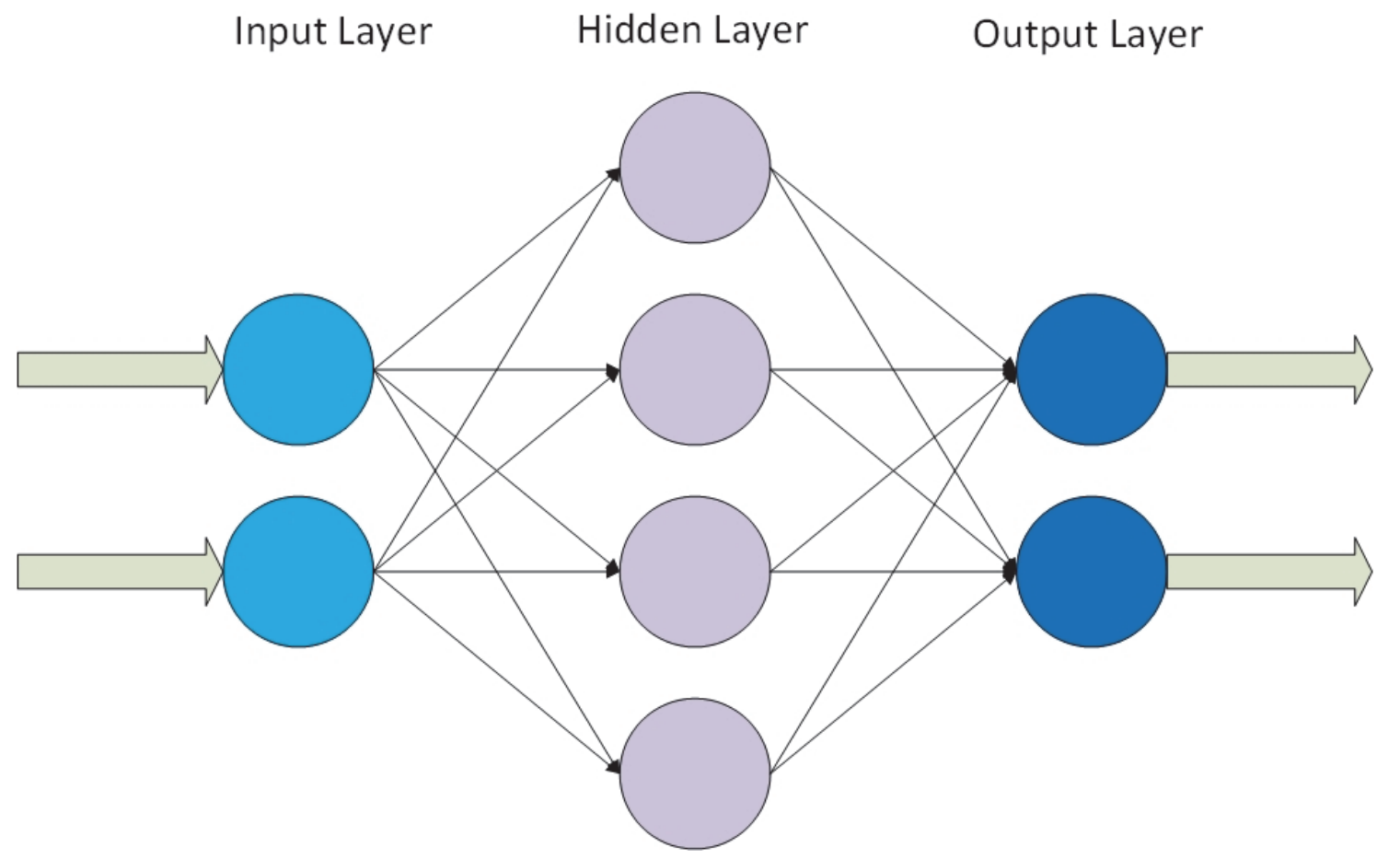

Fig. 3. Multi-Layer Perceptron(MLP) model

\subsection{Data set description}

The data in this paper comes from 3 CCPP modules in a time span of 4 months. The data was collected using the power plants automation system which collect all of the operational data from the installed transmitters in a time span of 6 months. The features monitored are shown in Table 1 for the ST and HRSG network and in Table 2 for the MCS network. The data is in hourly format. Circulation pump status is 1 for 1 pump in operation and 2 for 2 pumps in use. 
Table 1

Steam Turbine data structure

\begin{tabular}{lll}
\hline & Unit & Feature \\
\hline \multirow{3}{*}{ Input } & MV & GT load \\
& Celsius & Ambient Temperature \\
\hline Output & mbar & Vacuum \\
\hline
\end{tabular}

Table 2

Main Cooling System data structure

\begin{tabular}{lll}
\hline & Feature & Unit \\
\hline & Water Temp Sector 1 & Celsius \\
& Water Temp Sector 2 & Celsius \\
& Water Temp Sector 3 & Celsius \\
& Water Temp Sector 4 & Celsius \\
Input & Water Temp Sector 5 & Celsius \\
& Water Temp Sector 6 & Celsius \\
& Peak cooler 1 Temp & Celsius \\
& Peak cooler 2 Temp & Celsius \\
& Circulation pump & Ampere \\
& ambient temperature & Celsius \\
\hline Output & Vacuum & mbar \\
\hline
\end{tabular}

\section{Study procedure}

\subsection{Data preprocessing and transformation}

Data preprocessing and transformation is a vital part of every machine learning project. The data collected from the power plant data warehouse was in text format. First of all, the data was transferred to Microsoft Excel program. Then the data from each module was separated in different spreadsheets. During this time span of data collection, there were times when one GT was disconnected from the power grid due to emergency or maintenance programs. Also, there were occasions when the GT was in operation but the corresponding HRSG was out of service and ST was operating by one HRSG. The exhaust gas temperature was evaluated and when this number was below 400 degrees of Celsius threshold, the record was deleted from the data set. This also account for the elimination of transient phases in the data and ensure that all data are within the steady state phase of operation. Beside this, in some records there was a fuel change over in the GT which causes a transient phase in both the GT and HRSG. The fuel consumption record of the power plant was observed and those records in which there were a fuel change was deleted. An example of processed data for GT and HRSG is shown in table 3. An example of data distribution of vacuum pressure and Steam Turbine output can be seen in Fig. 4 and Fig. 5.

Table 3

The processed data for GT and HRSG

\begin{tabular}{lllllll}
\hline Exhaust & \multicolumn{1}{l}{ MV } & Exhaust & \multicolumn{1}{c}{ MV } & mbar & TEMP. & MV \\
\hline $\mathbf{5 2 4 . 6 5}$ & 119.97 & 525.77 & 123.048 & 111.252 & 10.694 & 109.52 \\
$\mathbf{5 2 4 . 1 1 3}$ & 115.357 & 526.325 & 118.025 & 110.976 & 10.547 & 106.45 \\
$\mathbf{5 2 4 . 3 0 1}$ & 90.081 & 526.418 & 89.928 & 120.486 & 10.01 & 87.297 \\
$\mathbf{5 2 4 . 4 0 4}$ & 90.082 & 526.45 & 89.823 & 121.572 & 9.525 & 87.312 \\
$\mathbf{5 2 4 . 3 5 8}$ & 90.05 & 526.418 & 90.089 & 123.472 & 9.994 & 87.4 \\
$\mathbf{5 2 4 . 3 5 8}$ & 89.703 & 526.39 & 89.919 & 121.4 & 9.736 & 87.152 \\
$\mathbf{5 2 4 . 3 7 5}$ & 90.207 & 526.411 & 90.403 & 121.289 & 9.142 & 87.286 \\
\hline
\end{tabular}




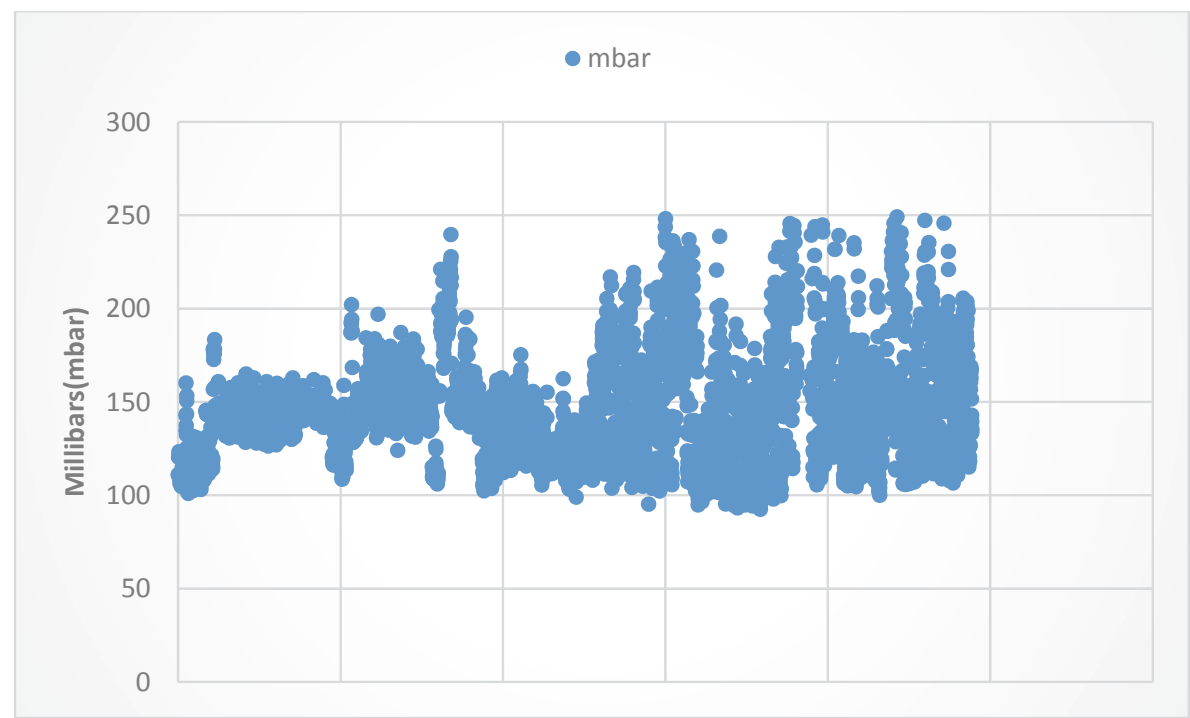

Fig. 4. vacuum pressure distribution

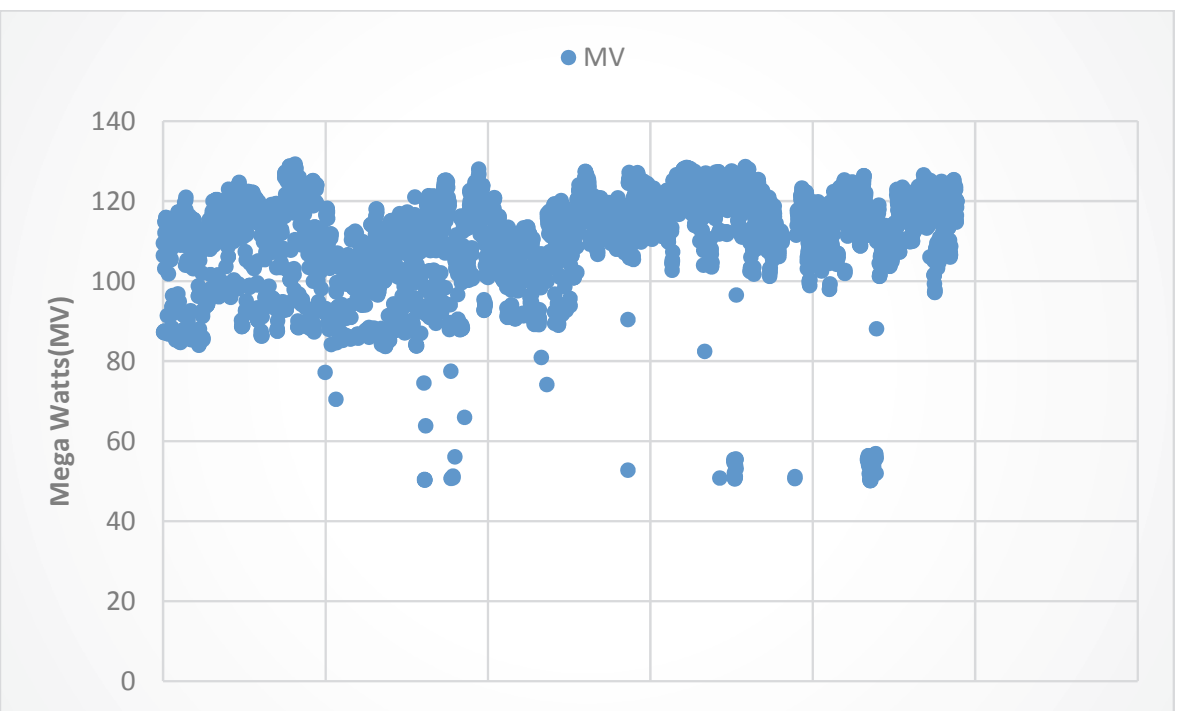

Fig. 5. ST output distribution

In the MCS section, the Ampere of each Circulation Water Pump(CWP) was changed to a 1-2 format; 1 indicating one CWP in service and 2 showing two CWPs in service. The main return line Temp. was divided by the outer Temp of each sector. The number obtained shows the performance level of each sector which is known by the module operators. If the number exceeds 1.4 , the sector is out of service and 0 is replaced showing ANN the difference between in service and out of service sectors.

\subsection{ANN modeling}

The modeling was done using MLP with back propagation. In this ANN model, the data is transmitted through the model layer by layer and the output is calculated. The weights matrix in this forward pass are randomized. The derived outputs are compared with the desired outputs and the error (mean squared error) is calculated and used in a backward pass to re-calculate the matrix weights in order to decrease the error. This process is called supervised machine learning. The process of going through all the data and calculating the weights matrix is called an iteration or epoch. This iterative process is repeated until an acceptable level of error is reached. This process is called error back propagation training. The 
"trainlm" function from Matlab ANN toolbox was used which updates weight and bias values according to Levenberg-Marquardt optimization technique. Also, the cross- validation check was used, i.e. Validation vectors are used to stop training early if the network performance on the validation vectors fails to improve or remains the same for 6 epochs in a row. Test vectors are used as a further check that the network is generalizing well, but do not have any effect on training. The data is divided randomly to 70 percent training, 15 percent validation and 15 percent testing data. The performance was checked and when the validation set's MSE did not decrease, training was automatically stopped. By trial and error, one hidden layer with 30 neurons gave the best results.

\subsubsection{MCS modeling}

The ANN modeling of the main cooling system was carried out with 30 neurons in one hidden layer. Fig. 6 shows the performance of the ANN model. At epoch 14 the validation MSE was 63.02. The picture shows there is a good convergence between the training validation and test sets.

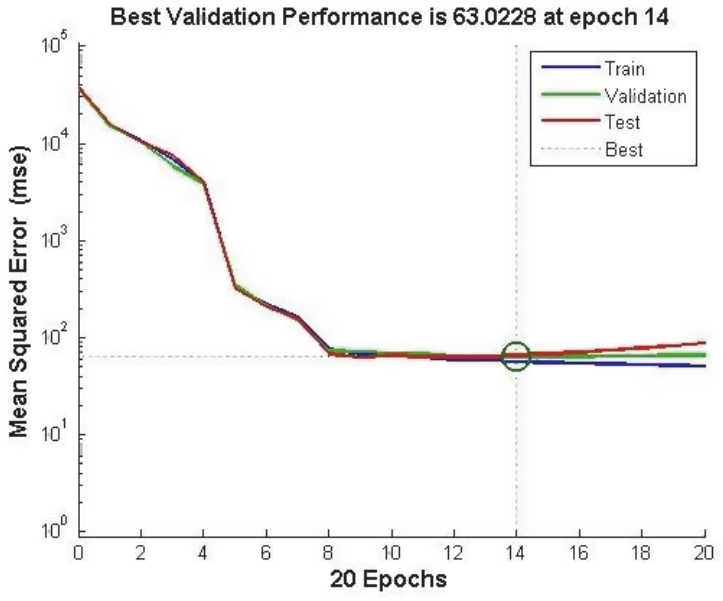

Fig. 6. performance of MCS model
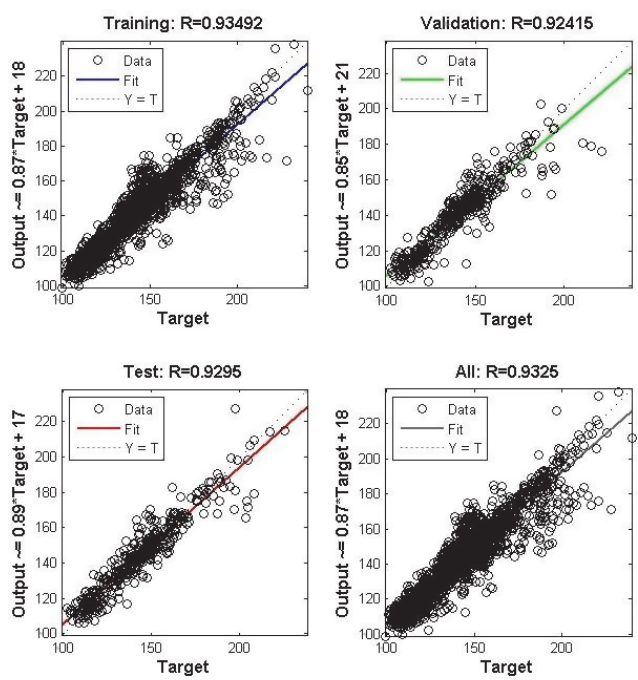

Fig. 7. Regression diagrams of MCS model

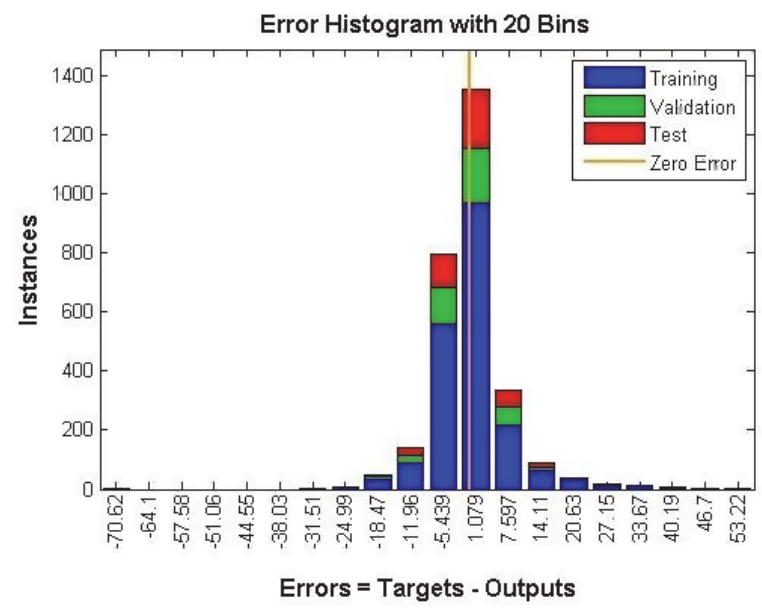

Fig. 8. Error histogram of MCS model 
Fig. 7 shows the Regression plots of the three sets. The regression value $\mathrm{R}$ measures the correlation between the target and the ANN output. As can be seen, there is a strong relationship between the actual vacuum value and the predicted value by the model. Fig. 8 shows the error histogram in 20 bins. The plot shows a uniform error pattern in the test, validation and training sets.

Table 4

Performance analysis of MCS model (mean squared error)

\begin{tabular}{ll}
\hline & ANN model performance(MSE) \\
\hline Training & 56.4 \\
Validation & 63 \\
Test & 65 \\
\hline
\end{tabular}

\subsubsection{ST and HRSG modeling}

ST modeling was done with the model described above. The input data for the analysis were the exhaust temperature of the GTs and the corresponding load in Mega Watts (MV), the ambient temperature and the vacuum at the last section of the steam turbine. The output was the ST electricity production in megawatts. After 41 iterations the ANN model arrived at a good performance (Fig. 9) regression plots show acceptable correlation between input and output data (Fig. 10). Also the uniformity of the error produced in the neural network model shows the model was successful at predicting the power output.

Table 5

Performance analysis of ST model (mean squared error)

\begin{tabular}{ll}
\hline & ANN model performance(MSE) \\
\hline Training & 56 \\
Validation & 65 \\
Test & 62 \\
\hline
\end{tabular}

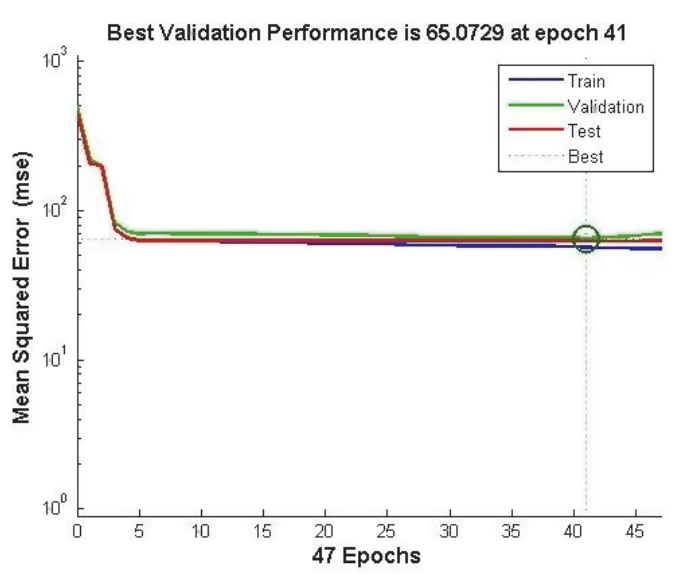

Fig. 9. performance of ST model
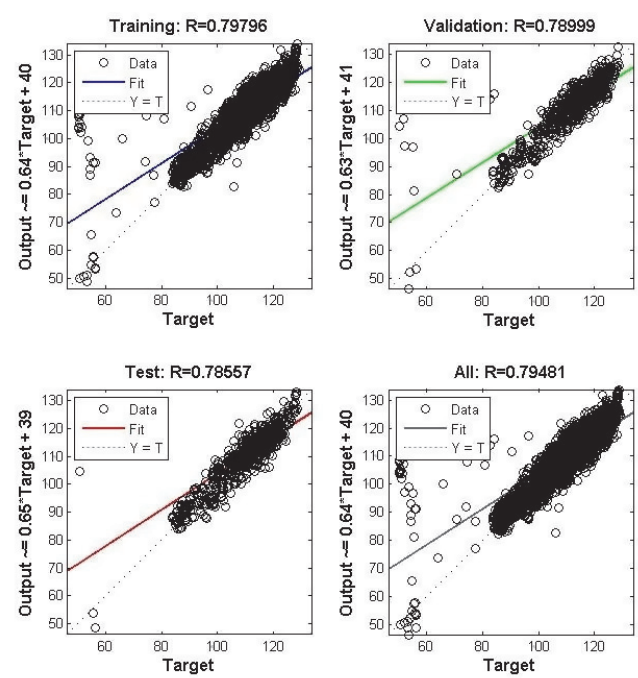

Fig. 10. Regression diagrams of ST model 


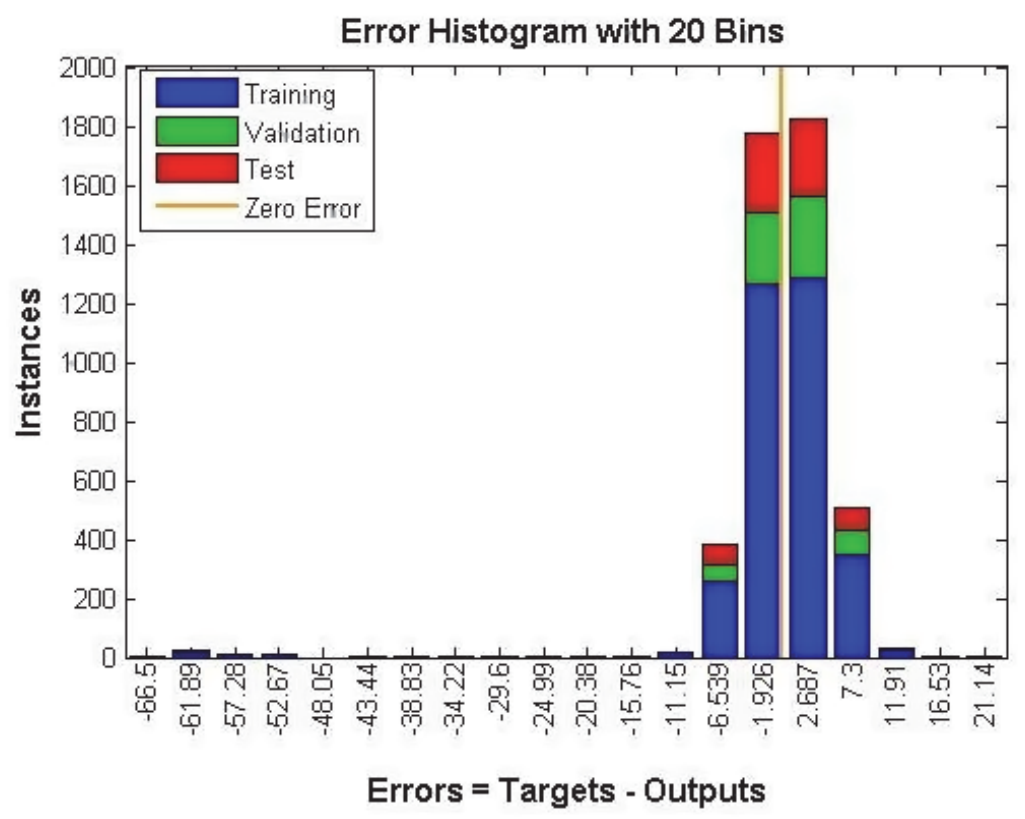

\subsection{Sensitivity analysis}

Fig. 11. Error histogram of ST model

The purpose of sensitivity analysis is to measure the relationship between output and input data. The first choice of parameters was based on expert knowledge of the system and availability of reliable data. The ANN model does not take into account the physical dependences of the input parameters and the output. For this reason, the dependency of output to each parameter has to be investigated. The prediction accuracy (MSE) of the trained ANN is compared with and without the selected parameter; if the MSE is not affected in spite of the parameter removal, one can conclude that the parameter is not related to the output and can be deleted from the ANN model. On the other hand, if the model accuracy is reduced, the interdependency of the input and output parameter can be confirmed. In the MCS model, the CWP number, GT output and GT exhaust gas temperature effect on the accuracy of the ANN model were examined. In the ST model ambient temperature and GT load effect were examined. Each of these input parameters were removed and the ANN model was retrained and the final MSE was calculated. The results can be seen in Tables 6 and 7. In the MCS model, the results show that deleting GT parameters and CWP parameter both have adverse effects on the performance indicators; thus, both have interdependency to the output variable. In the ST model, both ambient temperature and GT load are dependent on the ST load, i.e. the output.

Table 6

Sensitivity analysis of MCS model

\begin{tabular}{cccc}
\hline ANN model without GT parameters & \multicolumn{3}{c}{ ANN model without CWP number } \\
\hline Training & $\mathbf{6 3 . 7}$ & Training & $\mathbf{7 2 . 8}$ \\
Validation & $\mathbf{6 9 . 5}$ & Validation & $\mathbf{1 1 2 . 7}$ \\
Test & $\mathbf{9 3 . 4}$ & Test & $\mathbf{8 2 . 4}$ \\
\hline
\end{tabular}

Table 7

Sensitivity analysis of ST model

\begin{tabular}{cccc}
\hline ANN model without ambient Temp. & \multicolumn{3}{c}{ ANN model without GT load } \\
\hline Training & $\mathbf{6 4}$ & Training & $\mathbf{7 3}$ \\
Validation & $\mathbf{7 4}$ & Validation & $\mathbf{9 8}$ \\
Test & $\mathbf{4 9}$ & Test & $\mathbf{8 0}$ \\
\hline
\end{tabular}




\section{Conclusion and future research}

In this study, the steam turbine of a combined cycle power plant with dry cooling tower was modeled using MLP with back propagation training. First of all, the main cooling system was modeled to predict the cooling capacity in the steam turbine exhaust using the data available to the operator. In this manner, the operators are able to predict the exhaust steam vacuum of the ST, which is critical in the ST output, with good accuracy. Then the data was used to predict the power output of the ST using data available to the operators through the power plant's data warehouse. It can be seen that ANN modeling is capable of predicting the electrical production of ST under varying load conditions of two gas turbines.

The prediction can be utilized in two ways. First, it can be integrated in a dynamic condition monitoring system in which the online performance is compared to the derived model and any deviations are diagnosed and inspected. This can ensure safe and reliable operation in various conditions. Second, the model can be used for accurate power production forecasts. These forecasts are used in the electrical power market.

For future research, the HRSG and ST system can be modeled separately in order to arrive at an even more accurate ST model. At the next step, the GT, HRSG, MCS and ST models can be integrated to form a complete CCPP model.

\section{References}

Åström, K. J., \& Bell, R. D. (2000). Drum-boiler dynamics. Automatica, 36(3), 363-378.

Bassel, W. S., \& Gomes, A. V. (2002). A metastable wet steam turbine stage model. Nuclear Engineering and Design, 216(1), 113-119.

Bettocchi, R., Spina, P. R., \& Torella, G. (2002, January). Gas Turbine Health Indices Determination by Using Neural Networks. In ASME Turbo Expo 2002: Power for Land, Sea, and Air (pp. 10831089). American Society of Mechanical Engineers.

Bhambare, K. S., Mitra, S. K., \& Gaitonde, U. N. (2007). Modeling of a coal-fired natural circulation boiler. Journal of Energy Resources Technology, 129(2), 159-167.

Boccaletti, C., Cerri, G., \& Seyedan, B. (2000, May). A neural network simulator of a gas turbine with a waste heat recovery section. In ASME Turbo Expo 2000: Power for Land, Sea, and Air (pp. V003T02A008-V003T02A008). American Society of Mechanical Engineers.

Embrechts, M. J., Schweizerhof, A. L., Bushman, M., \& Sabatella, M. H. (2000, May). Neural network modeling of turbofan parameters. In ASME Turbo Expo 2000: Power for Land, Sea, and Air (pp. V004T04A008-V004T04A008). American Society of Mechanical Engineers.

Escarela-Perez, R., Arjona-Lopez, M. A., Melgoza-Vazquez, E., Campero-Littlewood, E., \& AvilesCruz, C. (2004). A comprehensive finite-element model of a turbine-generator infinite-busbar system. Finite Elements in Analysis and Design, 40(5), 485-509.

Ferretti, G., \& Piroddi, L. (2001). Estimation of NOx emissions in thermal power plants using neural networks. Journal of Engineering for Gas Turbines and Power, 123(2), 465-471.

Kesgin, U., \& Heperkan, H. (2005). Simulation of thermodynamic systems using soft computing techniques. International Journal of Energy Research, 29(7), 581-611.

Kumar, A., Srivastava, A., Banerjee, A., \& Goel, A. (2012). Performance based anomaly detection analysis of a gas turbine engine by artificial neural network approach. In Procee. Annual conference of the prognostics and health management society.

Liu, C. L., Niu, Y. G., Liu, J. Z., \& Jin, X. Z. (2001a). A Boiler Model of 300MW Power Unit for Control System Performance Studies. Acta Simulata Systematica Sinica S, 1.

Liu, J., Cui, Y., \& Jiang, H. (2001b). Investigation of flow in a steam turbine exhaust hood with/without turbine exit conditions simulated. In ASME Turbo Expo 2001: Power for Land, Sea, and Air (pp. V001T03A072-V001T03A072). American Society of Mechanical Engineers. 
Lampart, P., \& Yershov, S. (2003). Direct constrained computational fluid dynamics based optimization of three-dimensional blading for the exit stage of a large power steam turbine. Journal of Engineering for Gas Turbines and Power, 125(1), 385-390.

Rich, E., \& Knight, K. (1991). Artificial intelligence. $2^{\text {nd }}$ ed. McGraw- Hill, Inc.

Russell, S., Norvig, P., \& Intelligence, A. (1995). Artificial Intelligence. Prentice-Hall, Egnlewood Cliffs, 25, 27.

Perryman, R., \& Perrott, S. N. (1994, December). Condition monitoring and predictive analysis of combined heat and power systems. In Life Management of Power Plants, 1994., International Conference on (pp. 40-47). IET.

DePold, H. R., \& Gass, F. D. (1998, June). The application of expert systems and neural networks to gas turbine prognostics and diagnostics. In ASME 1998 International Gas Turbine and Aeroengine Congress and Exhibition (pp. V005T15A009-V005T15A009). American Society of Mechanical Engineers.

Olausson, P. (2003). On the selection of methods and tools for analysis of heat and power plants. Division of Thermal Power engineering, Lund Institute of Technology, PO Box 118, SE-221 00 LUND, Sweden.

Rahnama, M., Ghorbani, H., \& Montazeri, A. (2012, December). Nonlinear identification of a gas turbine system in transient operation mode using neural network. In Thermal Power Plants (CTPP), 2012 4th Conference on (pp. 1-6). IEEE.

Schobeiri, M. T., \& Chakka, P. (2002). Prediction of turbine blade heat transfer and aerodynamics using a new unsteady boundary layer transition model. International Journal of Heat and Mass Transfer, 45(4), 815-829.

Tayarani-Bathaie, S. S., Vanini, Z. S., \& Khorasani, K. (2014). Dynamic neural network-based fault diagnosis of gas turbine engines. Neurocomputing, 125, 153-165.

Tüfekci, P. (2014). Prediction of full load electrical power output of a base load operated combined cycle power plant using machine learning methods. International Journal of Electrical Power \& Energy Systems, 60, 126-140.

Yari, M., Shoorehdeli, M. A., \& Yousefi, I. (2013, February). V94. 2 gas turbine identification using neural network. In Robotics and Mechatronics (ICRoM), 2013 First RSI/ISM International Conference on (pp. 523-529). IEEE.

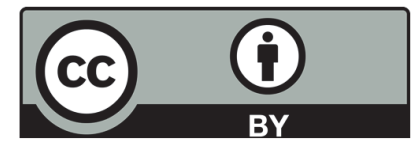

(C) 2017 by the authors; licensee Growing Science, Canada. This is an open access article distributed under the terms and conditions of the Creative Commons Attribution (CC-BY) license (http://creativecommons.org/licenses/by/4.0/). 